\title{
Psychological problems related to capillary blood glucose testing and insulin injection among diabetes patients
}

Review

Rian Adi Pamungkasa,**, Kanittha Chamroonsawasdib,\%

${ }^{a}$ Department of Nursing, Faculty of Health Sciences, Esa Unggul University, Jakarta 11470, Indonesia

${ }^{b}$ Department of Family Health, Faculty of Public Health, Mahidol University, Bangkok 10400, Thailand

Received: 23 October 2019; Accepted: 22 November 2019; Published: 20 June 2020

Abstract: 0 objective: This review is aimed at explaining the psychological problems related to capillary blood glucose (CBG) testing and insulin injection, as well as recommending essential strategies to solve the fear thereof.

Methods: Databases, including PubMed, Cumulative Index of Nursing and Allied Health Literature (CINAHL), Scopus, and Google Scholar, were searched to extract the relevant articles. Initially, the terms used to retrieve related studies were "fear of blood glucose monitoring", "anxiety capillary blood glucose testing and insulin injection", "psychological problems on blood glucose monitoring and insulin injection", "diabetes management", and "diabetes mellitus".

Results: Results showed that the psychological problems related to CBG testing and insulin injection were associated with the stress and depression experienced during diabetes self-monitoring of blood glucose. This psychological issue has its impacts such as nonadherence to medication as well as a lack of self-discipline in terms of CBG testing and insulin injection. Inadequate information, inappropriate perception, and pain/discomfort during pricking of fingers were the main reasons for the psychological issues in CBG testing and self-injection of insulin.

Conclusions: The expected benefits of this review include the explanation of the issues related to the psychological problems in CBG testing and insulin injection among type 2 diabetes mellitus (T2DM) patients. This review article also provides the recommendations on providing counseling and empowering the patients on CBG monitoring and insulin injection. Moreover, family members should provide psychological support to reduce fear, anxiety, and distress arising from CBG testing and insulin injection.

Keywords: diabetes mellitus $\bullet$ psychological problems • capillary blood glucose testing • insulin injection

(c) Shanxi Medical Periodical Press.

\section{Introduction}

Capillary blood glucose (CBG) testing and insulin injection are essential strategies to monitor the blood glucose level and to support a successful diabetes selfmanagement behavior among patients with diabetes mellitus (DM). Globally, the percentage of blood glucose tests undertaken for controlling and managing blood glucose concentration is lower among DM patients. A recent study conducted in Nigeria showed that only $47.8 \%$ of patients conducted CBG testing. ${ }^{1}$ The study also found that in Spain, only $52 \%$ patients conducted CBG testing for managing blood glucose levels. ${ }^{2}$

CBG testing and insulin injection have been widely recommended for patients and health-care providers

How to cite this article: Pamungkas RA, Chamroonsawasdi K. Psychological problems related to capillary blood glucose testing and insulin injection among diabetes patients. Front Nurs. 2020; 2: 87-96.

* Corresponding authors.

E-mail: rian.adi@esaunggul.ac.id (R. -A. Pamungkas); kanittha.cha@mahidol.ac.th (K. Chamroonsawasdi).

O Open Access. @ 2020 Pamungkas and Chamroonsawasdi, published by Sciendo. (c) Br-Nc-ND This work is licensed under the Creative Commons Attribution NonCommercial-NoDerivatives 4.0 License. 
as an integrated part of DM self-management (DMSM) practice. $^{3}$ The frequency of self-testing among type 1 DM (T1DM) patients is approximately three times a day, while type $2 \mathrm{DM}$ (T2DM) patients are required to perform CBG testing and insulin injection two times daily. ${ }^{4}$ This has been recommended for both patients and their family members because it is easy, very cheap, and less invasive to perform at home so as to maintain a constant level of blood glucose by applying precise regimens. ${ }^{5}$ CBG testing and insulin injection can also improve the practice of self-monitoring of blood glucose (SMBG) and medication-taking among DM patients, ${ }^{6}$ as well as helping to detect hypoglycemia and to adjust their insulin dosage appropriately during DMSM practice in T2DM patients. ${ }^{6,7}$

The CBG testing and insulin injection processes tend to have positive effects on management of the blood glucose level; however, their impact as a psychological effect on the patient's uptake and adherence to CBG testing, as well as insulin injection, remains significant and essential for DM patients to cope with. ${ }^{8}$

Intense fear of self-injection is the most plausible reason for the precipitation of psychological distress. ${ }^{9}$ Moreover, CBG monitoring or pricking the finger may trigger distress and severely hamper self-management. ${ }^{10}$ This fear of CBG testing and insulin injection is often associated with nonadherence in DM patients, which leads to inadequate glycemic control ${ }^{8}$ and may increase the risk of severe diabetes complications. ${ }^{11}$

Recently, it has been recognized that there is still a gap in the analysis of psychological problems related to CBG testing and insulin injection. There have been only a few literature reviews concerning the psychological issues of CBG testing and insulin injection. This present review focuses on exploring the current information on fear and other psychological aspects of CBG testing and insulin injection to obtain valuable information for developing strategies to solve the problem of fear and to improve the quality of life among T2DM patients.

\section{Objectives}

This study is aimed at exploring and narratively describing studies related to the psychological problems faced during CBG testing and insulin injection among DM patients.

\section{Methods}

\subsection{Data sources and search strategy}

The databases, including PubMed, Cumulative Index of Nursing and Allied Health Literature (CINAHL), Scopus, and Google scholar, were searched to extract relevant articles. Initially, the terms used to extract related studies were "fear of blood glucose monitoring", "anxiety capillary blood glucose testing and insulin injection", "psychological problems on blood glucose monitoring and insulin injection", "diabetes management", and "diabetes mellitus". The keywords of "psychological problems on blood glucose testing and insulin injection" were the primary search terms and entered as the medical subject heading $(\mathrm{MeSH})$ in the abstract and title fields. The details are summarized in Table 1.

\subsection{Eligibility criteria of the study}

The articles were selected based on the inclusion criteria, which included English language articles published between 2005 and 2017. The researchers also included several types of study designs, including a survey, a descriptive study, a qualitative study, a quasiexperimental study, a randomized controlled trial, and a mixed-method design, in the screening process.

\subsection{Exclusion criteria of the study}

Lack of description of appropriate outcome measures (e.g., studies in which psychological aspects were not included as the primary outcomes) were excluded from this review. Unpublished articles and articles reporting on inappropriate populations, such as people with gestational diabetes or other metabolic diseases, also were excluded.

\section{Theoretical framework}

The conceptual framework of this study was based on a stress-adaptation model that explained the process of adaptation specific to adults with T2DM, proposed by Pollock. ${ }^{12}$ The manner in which patients adapt to the stress of diabetes is affected, or mediated, by how

\begin{tabular}{|c|c|}
\hline Sources of data & Keywords \\
\hline PubMed & $\begin{array}{l}\text { * Fear AND Capillary blood glucose OR Insulin } \\
\text { injection AND Diabetes } \\
\text { * Psychological problem on capillary blood } \\
\text { glucose OR Insulin injection AND Diabetes }\end{array}$ \\
\hline Scopus & $\begin{array}{l}\text { * Fear AND Capillary blood glucose OR Insulin } \\
\text { injection AND Diabetes } \\
\text { * Psychological problem on capillary blood } \\
\text { glucose OR Insulin injection AND Diabetes }\end{array}$ \\
\hline CINAHL & $\begin{array}{l}\text { * Fear AND Capillary blood glucose OR Insulin } \\
\text { injection AND Diabetes } \\
\text { * Psychological problem on capillary blood } \\
\text { glucose OR Insulin injection AND Diabetes }\end{array}$ \\
\hline Google Scholar & $\begin{array}{l}\text { *Fear AND Capillary blood glucose OR Insulin } \\
\text { injection AND Diabetes } \\
\text { * Psychological problem on capillary blood } \\
\text { glucose OR Insulin injection AND Diabetes }\end{array}$ \\
\hline
\end{tabular}

Table 1. Database search and keywords. 
they cope with the fear and anxiety of diabetes. Thus, improvements in blood glucose control are proposed in relation to coping, self-efficacy, family functioning, and self-management as mediating factors (Figure 1).

\section{Synthesis of the results}

The findings of this study are described narratively according to the thematic framework composed of the following:

(1) Definition of CBG testing and insulin injection;

(2) Psychological barriers related to CBG testing and insulin injection;

(3) Factors related to fear and psychological issues in the context of CBG testing and insulin injection;

(4) Impacts of psychological problems in CBG testing and insulin injection;

(5) Strategies to manage the psychological problems related to CBG testing and insulin injection; and

(6) Recommendation to manage psychological problems in CBG testing and insulin injection.

\section{Results}

The results of this study are expressed based on the thematic framework as follows.

\subsection{Definition of CBG monitoring and insulin injection}

\subsubsection{CBG monitoring}

CBG testing can be defined as a method of checking the blood glucose concentration in patients with hyperglycemic or hypoglycemic conditions. ${ }^{13}$ Blood glucose testing is typically done by piercing the skin at the fingertip and then applying the blood to a chemically active disposable strip. SMBG is a strategy for health-care providers and patients to assess the effectiveness and safety of a self-management plan in terms of glycemic control. In addition to intervention, the benefits of intensive glycemic control on the prevention and reduction of complications due to diabetes can be demonstrated. ${ }^{14}$

Using the CBG monitoring technique, patients can evaluate their response to a therapy and can assess whether the blood glucose level meets the target or not. ${ }^{13}$ Incorporation of CBG testing with DMSM practice can be an essential instrument to guide medical nutrition therapy, adopt proper kind of physical activity, prevent hypoglycemic complications, and adjust medications for patients who take prandial insulin doses. ${ }^{13,15}$

Optimal CBG monitoring requires patients and health-care providers to properly review and interpret the results. Therefore, patients should understand how to use blood glucose data to adjust their food intake, get adequate physical exercise, or adopt medication therapy to achieve the desired blood glucose control. The frequency of blood glucose monitoring should be reevaluated to avoid overuse. ${ }^{16,17}$

\subsubsection{Insulin injection}

Insulin injection is used among T2DM patients when they have the problem of insulin being broken down by their digestive enzyme and hence insulin cannot be substituted in the oral pill form. Insulin injection is delivered by three techniques, as follows. (1) Syringe and needle are used to push the insulin into a layer of fat below the skin, called as the "subcutaneous tissue".

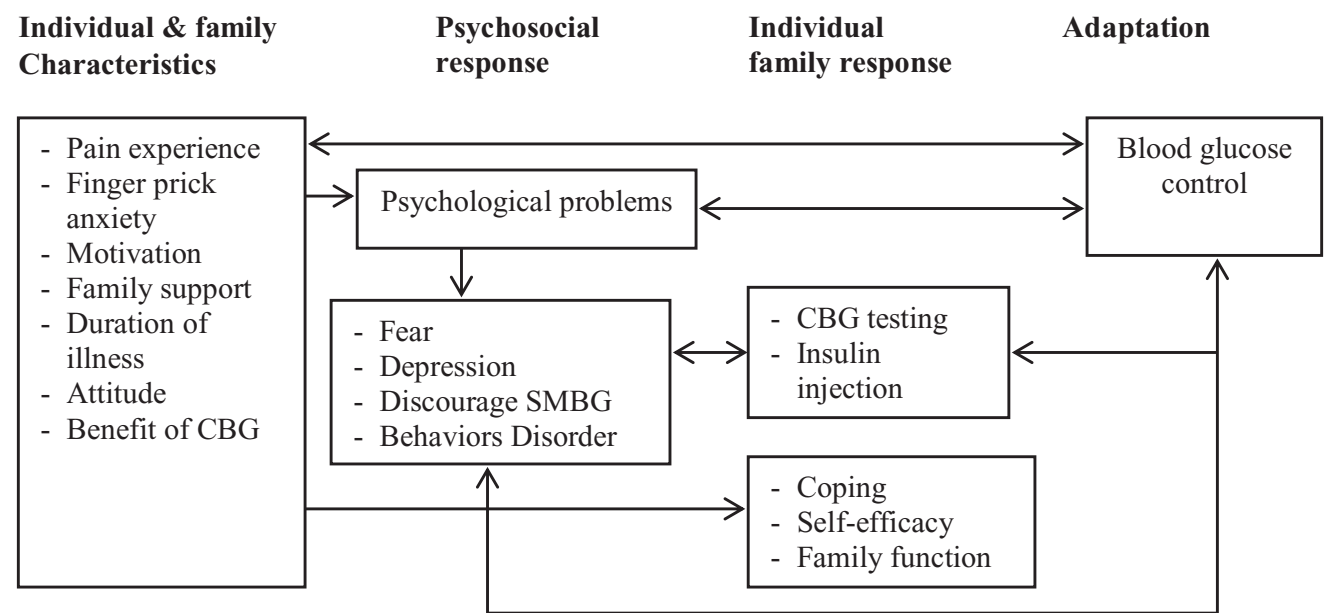

Figure 1. Conceptual model of psychological adaptation for diabetes mellitus. 
Usually, the layers of fat may be selected from among the following sites for the easy absorption of insulin into the blood stream: abdomen, hips, thighs, buttocks, and the back of the arms. The injection site can be changed every 2-3 days to reduce pain and lesions. (2) Insulin pens containing insulin instead of ink are used to deliver insulin at a set dose with a disposable needle. Pen needles can be applied with a variety of lengths and thicknesses of the injection areas. The pen method is considered to be more convenient and accurate to use when compared with the syringe method. (3) Electronic insulin pumps to continuously deliver insulin into the fat layer. This method is appropriate for those T2DM patients who need multiple injections per day of insulin. ${ }^{18}$

\subsection{Psychological barriers related to CBG testing and insulin injection}

Psychological barriers are proved to have adverse effects on DMSM practice (Table 2). Similarly, psychological barriers are mainly affected by inappropriate perception and negative attitude on CBG testing and insulin injection. Psychological problems, such as fear of needles, stress, emotions, and bad experience, are associated with nonadherence and lack of self-discipline in CBG monitoring and insulin injection. ${ }^{19}$

Dealing with the results of blood glucose tests is also a critical issue in CBG testing. Frustration related to high blood glucose reading and negative appraisal could decrease the CBG frequency. ${ }^{19,20}$ Many patients are often discouraged in their efforts toward self-regulation when faced with adverse health outcomes. ${ }^{21}$ Moreover, depressed and anxious diabetic patients who often face repeated failures in maintaining their blood glucose level in accordance with normal levels are prone to emotional exhaustion and apathy, even uncontrollable stress. ${ }^{21}$ Moreover, the failure of physicians in discussing the CBG results in a positive manner becomes a significant reason for patients avoiding CBG testing or insulin injection. ${ }^{22}$

The apparent fear and other psychological issues related to $\mathrm{CBG}$ testing and insulin injection require further interest from health-care professionals. Diabetes professionals should be sensible persons who pay attention to the patients' psychological needs regarding CBG testing and its results and, in addition, be able to offer patients problem-solving assistance and promote relaxation techniques to enhance coping skills and selfefficacy in dealing with DM. Offering a "team" approach to address barriers and involving the patients in the analysis of their response to SMBG practice is essential for resolving conflicts within families. ${ }^{23}$

Psychological problems related to insulin injection induce delay of treatment as a result of clinical inertia and insulin resistance. The clinical problems include misconception on the effectiveness of insulin injection, the belief that starting insulin is a sign of treatment failure, fear of and pain during injection by needles, and fear of their suffering from hypoglycemic/hyperglycemic symptoms. ${ }^{24}$

A meta-analysis in one study summarized the psychological problems related to insulin therapy among T2DM patients and indicated that the risk of depression was more among patients with long-term treatment using insulin injection. ${ }^{25}$

From its initiation, further counseling and education using concepts related to patient-orientated standard of care should be emphasized; precise knowledge of the psychological aspects of treatment and counseling

\begin{tabular}{|c|c|c|}
\hline Authors & Study designs & Psychological issues related to CBG testing and insulin injection \\
\hline Ong et al. $2014^{19}$ & Qualitative design & $\begin{array}{l}\text { - Fear of needles and the fingertip pricking being painful } \\
\text { - Frustration related to high blood glucose reading } \\
\text { - Lack of motivation of SMBG }\end{array}$ \\
\hline Taylor et al. $2017^{26}$ & $\begin{array}{l}\text { Mixed qualitative and } \\
\text { quantitative design }\end{array}$ & $\begin{array}{l}\text { - Stress and emotions described as shame, laziness, and forgetfulness among patients, family } \\
\text { members, and community members }\end{array}$ \\
\hline $\begin{array}{l}\text { Van Dooren et al. } \\
2016^{27}\end{array}$ & Cohort study & $\begin{array}{l}\text { - High levels of depressive and anxiety symptoms related to diabetes management } \\
\text { - Personality traits including negative affectivity, the tendency to experience negative emotions } \\
\text { across situations and during social interaction } \\
\text { - The tendency to inhibit the expression of feelings in social interactions to avoid disapproval }\end{array}$ \\
\hline Gucciardi et al. $2013^{20}$ & Qualitative design & $\begin{array}{l}\text { - Negative emotional responses to unexpected blood glucose readings, burden of SMBG, and } \\
\text { lack of self-discipline }\end{array}$ \\
\hline Shlomowitz et al. $2014^{8}$ & Cross-sectional study & $-58 \%$ of patients presented finger prick anxiety and $30 \%$ of patients had general anxiety \\
\hline Yoshioka $2018^{24}$ & Editorial & $\begin{array}{l}\text { - Misconception on effectiveness of insulin injection } \\
\text { - Fear of and pain during injection by needles } \\
\text { - Fear of their suffering from hypoglycemic/hyperglycemic symptoms } \\
\text { - Wrong belief on insulin injection as treatment failure }\end{array}$ \\
\hline Bai et al. $2018^{25}$ & Meta-analysis & - Depression on long-term insulin therapy \\
\hline
\end{tabular}

Table 2. Psychological issues related to $\mathrm{CBG}$ testing and insulin injection. 
techniques are important to maintain the adherence to DMSM practice, CBG testing, and insulin injection among T2DM patients.

\subsection{Factors related to psychological problems in the context of CBG testing and insulin injection}

Table 3 summarizes the factors related to psychological problems and its impacts on CBG testing and insulin injection. The psychological aspects related to CBG testing and insulin injection have become a significant issue in DMSM practice. These psychological issues are mainly concerned with insufficient knowledge and inappropriate perception of CBG testing, including its benefits, indication, and side effects.

Experience of pain or discomfort while pricking the finger was the most common reason that discouraged DMSM practice, especially CBG testing or insulin injection. Pain associated with finger pricking is the main reason, apart from the costs, holding back patients from SMBG. This condition might also induce a negative perception of DMSM in general. Thus, convincing the patients, especially young ones, to measure blood glucose several times a day appears to be a trouble for health-care providers, patients, and families.

A study conducted by Shlomowitz et al. ${ }^{8}$ found that $30 \%$ of patients faced finger prick anxiety and $33 \%$ of patients had general anxiety. Positive correlations were found between finger prick anxiety and avoidance of CBG testing. This reluctance was more common in females who had an experience of pricking pain, in addition to forgetfulness, fear of results, boredom, and embarrassment related to public testing.

Another study showed some shreds of evidence on the level of anxiety in CBG testing. In a Dutch study, ${ }^{28}$ the psychological problem related to CBG monitoring was identified as emotional distress and avoidance lifestyle behaviors among diabetes patients with insulin dependence. Less than $10 \%$ of patients had high scores on the fear of insulin injection and CBG testing.
One-fourth of the patients refused to complete an additional self-testing of blood. ${ }^{28}$

The World Health Organization (WHO) has recommended practical guidelines on CBG monitoring in the context of the site of capillary testing in adult or pediatric patients. A lancet should be shorter than the estimated depth to avoid pressure compresses on the skin. ${ }^{29}$

\subsection{Impacts of psychological problems related to CBG testing and insulin injection}

The reasons for nonoptimal diabetes management with insulin injection or CBG testing are fear of injection, fear of discomfort from the needle, pain on pricking the finger, anxiety, and the stress due to complicated treatment and side effects of the dose. This psychological problem eventually has a negative impact, causing misconception toward glucose monitoring and nonadherence to medication, diabetes-related fear, stigma, and discouragement of patients from monitoring blood glucose or using insulin for treatment.

The Diabetes Attitudes, Wishes and Needs (DAWN) study ${ }^{31}$ reported that about $57 \%$ of diabetic patients feel discouraged from using insulin therapy because they are worried about the possibility of starting the treatment in future. The results were also quite similar in another study, ${ }^{2}$ which revealed that only $52 \%$ of T2DM patients monitor blood glucose for controlling the disease, while $48 \%$ feel reluctant to initiate CBG testing and insulin injection. Fear of insulin or fear of the needle may be associated with ineffective glycemic control and may reduce patients' health status and their quality of life..$^{9,32}$

\subsection{Strategies to manage the psychological problems related to CBG testing and insulin injection}

Self-testing and self-injection have become an essential part of management for diabetes patients who are

\begin{tabular}{|c|c|c|}
\hline Authors & Factors related to psychological problems & $\begin{array}{l}\text { Impacts of psychological problems on CBG testing and insulin } \\
\text { injection }\end{array}$ \\
\hline Ong et al. $2014^{19}$ & $\begin{array}{l}\text { - Patient's emotion } \\
\text { - Low support and insufficient knowledge }\end{array}$ & $\begin{array}{l}\text { - Misconception toward glucose monitoring and nonadherence to } \\
\text { medication taking }\end{array}$ \\
\hline Taylor et al. $2017^{26}$ & $\begin{array}{l}\text { - Insufficient knowledge related to SMBG } \\
\text { - Unclear communication between health-care } \\
\text { providers and patients }\end{array}$ & $\begin{array}{l}\text { - Misconception related to SMBG, influence of the diabetes-related } \\
\text { stigma, and physiological and psychological issues }\end{array}$ \\
\hline Nazmi et al. $2013^{30}$ & $\begin{array}{l}\text { - Experience of pain or discomfort while } \\
\text { pricking the finger }\end{array}$ & - Patients discouraged from monitoring blood glucose \\
\hline $\begin{array}{l}\text { Shlomowitz and Feher } \\
2014^{8}\end{array}$ & $\begin{array}{l}\text { - Experience of finger prick anxiety } \\
\text { - Injection pain }\end{array}$ & - Avoiding self-monitoring by CBG \\
\hline
\end{tabular}

Table 3. Factors related to fear and psychological issues of $C B G$ testing. 
taking insulin doses based on different levels of blood glucose. ${ }^{33}$ Effective diabetes management has demonstrated that intensive monitoring of $\mathrm{CBG}$ and other diabetes risk factors can delay the progression of complications due to diabetes. However, many patients are reluctant to adjust management intensively due to psychological problems related to CBG testing and hypoglycemic symptoms.

Specific strategies to approach the management of the psychological problems associated with CBG testing and insulin injection are limited. Snoek et al. ${ }^{21}$ have introduced the five-step psychosocial model of SMBG to reduce the psychological problems related to blood glucose monitoring. This model presents strategies to decide whether patients can perform CBG monitoring or not and then evaluate the outcomes to determine the perceived barriers and benefits of CBG monitoring for maintaining the blood glucose level. Understanding the fundamental psychological principles in blood glucose monitoring is a prerequisite to designing an effective program for patients who experience problems with CBG monitoring. Applying a new technological innovation is more likely to influence the precision of measurement and enable patient convenience. However, it is a fundamental challenge to manage negative feedback as a part of self-regulating behaviors.

Another study recommends a different approach, known as "cognitive behavioral therapy (CBT)", for managing the psychological problems related to CBG monitoring. This strategy applies an educational approach as the cornerstone of behavior change, followed by exploring the negative beliefs that generate a contrary conclusion, anxiety, depression, and guilt. ${ }^{34}$ The strategy also involves challenging negative thoughts and has been used to alter behaviors and to treat mood disorders among T2DM patients.

Blood glucose awareness training (BGAT) is a psychoeducational intervention to consistently demonstrate the ability of CBG testing in detecting and alleviating both hypoglycemic and hyperglycemic conditions while reducing the sequel of extreme blood glucose levels. This strategy applies didactic education, followed by empowerment of patients with information about BGAT and skills related to it. The last step of BGAT is to detect, anticipate, avoid, and treat extremes of blood glucose, a sequel of extreme blood glucose, and adverse psychological functioning. The fear and the depressive syndrome also need to be addressed in a systematic controlled manner to improve patients' health outcomes. ${ }^{35}$ The details are summarized in Table 4

\section{Discussion}

CBG testing and insulin injection comprises an essential strategy in insulin-treated T1DM and T2DM. This approach provides a more accurate pattern of daily blood glucose fluctuations, helps determine the effect of DMSM practice, and helps to avoid unrecognized hypoglycemia. ${ }^{37}$

Previous studies, including meta-analyses and systematic reviews, have reported a positive association between SMBG with behavioral change on the one hand and reduction in glycated hemoglobin $(\mathrm{HbA} 1 \mathrm{c})$ levels on the other. ${ }^{38,39} \mathrm{~A}$ recent study has also shown that a structured blood glucose-testing schedule has positive impacts on $\mathrm{HbA} 1 \mathrm{c}$ improvement after following the DMSM program. ${ }^{40}$

\begin{tabular}{|c|c|c|}
\hline Authors & Strategies & Description of the strategy \\
\hline Snoek et al. $2008^{21}$ & $\begin{array}{l}\text { A 5-step psychosocial model } \\
\text { of SMBG }\end{array}$ & $\begin{array}{l}\text { - Deciding whether or not to perform a test. This choice may be based on routine } \\
\text { - Deciding whether or not to perform an analysis; this choice is based on the method } \\
\text { - Behavioral psychology to predict the negative experience with SMBG } \\
\text { - Diabetes education and sufficient cognitive ability } \\
\text { - Immediate action of SMBG } \\
\text { - Appraisal of SMBG outcomes }\end{array}$ \\
\hline Welschen et al. $2013^{34}$ & $\begin{array}{l}\text { Cognitive behavioral therapy } \\
\text { (CBT) }\end{array}$ & $\begin{array}{l}\text { - The CBT explores the negative beliefs that generate a contrary conclusion, anxiety, } \\
\text { depression, and guilt. This strategy involves challenging negative thoughts and has been } \\
\text { used to alter behaviors and to treat mood disorders }\end{array}$ \\
\hline Funnell et al. $2004^{36}$ & $\begin{array}{l}\text { Confrontation, persistence, } \\
\text { and reality (CPR) strategy }\end{array}$ & $\begin{array}{l}\text { - The CPR focuses on confrontation and assessment of patient's obstacles, including } \\
\text { psychological issues } \\
\text { - Persistence is talking about the interaction and collaboration between patients and } \\
\text { health-care provider in diabetes care } \\
\text { - The reality aspect covers the ongoing monitoring process }\end{array}$ \\
\hline Cox et al. $2006^{35}$ & $\begin{array}{l}\text { Blood glucose awareness } \\
\text { training (BGAT) }\end{array}$ & $\begin{array}{l}\text { - This is a psychoeducational intervention that consists of education on blood glucose and } \\
\text { how diabetes management affects blood glucose level } \\
\text { - Empowering patients with such information and skills is through BGAT } \\
\text { - Detection of extreme blood glucose, a sequel to excessive blood glucose, and } \\
\text { psychological issues such as fear and depressive symptoms }\end{array}$ \\
\hline
\end{tabular}

Table 4. Strategies to manage the psychological problems related to CBG monitoring and insulin injection. 
Several psychological barriers are linked with CBG monitoring and insulin injection, including fear of needles, the fingertip pricking being painful, stress and frustration arising from blood glucose results, lack of motivation, negative emotional response, and high levels of depressive and anxiety symptoms. These barriers have a significant influence on medication adherence and blood glucose monitoring.

Some evidences show that depressive and emotional disorders, such as anxiety, stress, and distress, lead to cognitive decline. ${ }^{41}$ These are also linked to disability, lack of health-care use, and premature mortality. ${ }^{42}$ Although the psychological issues among DM patients are extensive, person-centered treatment of this chronic illness and psychological support are quite low. Only $48.8 \%$ receive a treatment focused on psychological support. ${ }^{43}$

Some authors propose different strategies and approaches, including the five-step psychosocial model of SMBG, CBT, CPR strategy, and BGAT. These strategies are effective in managing the psychological issues related to $C B G$ testing and insulin injection.

The American Association of Diabetes Educators ${ }^{18}$ recommends that the idea of CBG testing and insulin injection therapy should be introduced as early as possible in DM patients to decrease the psychological problems related to those treatments. Patients should have clarity and should be able to understand the importance of CBG testing and insulin injection, as well as the side effects of both the procedures.

\section{Conclusions}

This review confirms and describes the psychological aspects related to $\mathrm{CBG}$ testing and insulin injection among DM patients. The information obtained helps provide recommendations to reduce the psychological problems related to CBG testing and insulin injection.

\section{Recommendations to manage the psychological problems related to CBG testing and insulin injection}

Specific recommendations to manage the psychological problems arising from CBG testing and insulin injection can be summarized as follows.

\subsection{Recommendations for action}

(1) Provide individual counseling and share experiences on how to deal with psychological problems among T2DM patients so as to reduce fear, anxiety, and depressive symptoms related to CBG testing, insulin injection, and prognosis of diabetes.

(2) Empower T2DM patients on continuing DMSM management, especially with CBG monitoring and insulin injection.

(3) Strengthen family members' inclination to support and care for diabetes patients during daily life activities and to provide psychological support in motivating the patients to adhere to treatment.

(4) Enhance the knowledge and skills of T2DM patients in connection with CBG testing and insulin injection by participatory learning with coaching, to reduce wrong beliefs and misconceptions related to insulin therapy.

\subsection{Recommendations for further study}

Clinical inertia or failure of health-care providers to initiate or intensify insulin treatment for T2DM patients needs to be explored in a systematic manner by using concept analysis or systematic review and meta-analysis.

\subsection{Strengths and limitations}

Since this review provides valuable information regarding the psychological problems commonly faced by DM patients, the findings can be used as inputs for health-care providers before designing an appropriate program for DM patients who perform SMBG and self-injection of insulin. However, some limitations are still found in this study because we have analyzed the results in a narrative form rather than as a systematic review or meta-analysis. This is due to the difficulty in accessing primary data and the variability in study designs, which did not allow us to pool data as a metaanalysis study.

\section{Acknowledgments}

We thank Mahidol University for facilitating the database search for conducting this review. We extend our special thanks to the Layanan Beasiswa dan Pendanaan Riset Indonesia (LPDP) Scholarship scheme for supporting this study.

\section{Ethical approval}

Ethical issues are not involved in this paper.

\section{Conflicts of interest}

All contributing authors declare no conflicts of interest. 
1. Edah JO, Odoh G, et al. Self-monitoring of blood glucose in Jos, Nigeria. J Med Tropics. 2016;18:28.

2. Cano-Blanquer D, Cervera-Casino P, Peiró-Moreno S, Mateu-García M, Barreda-Aznar A; Grupo de Estudio de la Automonitorización Glucémica. Prevalence and associated factors in self-monitoring of blood glucose in noninsulin-treated type 2 diabetes patients in the Valencia Community, Spain. Rev Esp Salud Publica. 2013;87:149-163.

3. American Diabetes Association (ADA). Standards of medical care in diabetes - 2009. Diabetes Care. 2009;32(Suppl 1):S13-S61.

4. Elgart JF, González L, Prestes M, Rucci E, Gagliardino JJ. The frequency of self-monitoring blood glucose and attainment of $\mathrm{HbA} 1 \mathrm{c}$ target values. Acta Diabetol. 2016;53:57-62.

5. Farhan SA, Shaikh AT, Zia M, et al. Prevalence and predictors of home use of glucometers in diabetic patients. Cureus. 2017;9:e1330.

6. American Diabetes Association (ADA). Standards of medical care in diabetes - 2013. Diabetes Care. 2013;36(Suppl 1):S11-S66.

7. Canadian Diabetes Association Clinical Practice Guidelines Expert C, Cheng AY. Canadian Diabetes Association 2013 clinical practice guidelines for the prevention and management of diabetes in Canada. Introduction. Can J Diabetes. 2013;37(Suppl 1): S1-S3.

8. Shlomowitz A, Feher MD. Anxiety associated with self-monitoring of capillary blood glucose. Br J Diabetes. 2014;14:60.

9. Fu AZ, Qiu Y, Radican L. Impact of fear of insulin or fear of injection on treatment outcomes of patients with diabetes. Curr Med Res Opin. 2009;25:1413-1420.

10. Mollema ED, Snoek FJ, Pouwer F, Heine RJ, van der Ploeg HM. Diabetes fear of injecting and selftesting questionnaire: a psychometric evaluation. Diabetes Care. 2000;23:765-769.

11. Pamungkas RA, Chamroonsawasdi K, Vatanasomboon P. A systematic review: family support integrated with diabetes self-management among uncontrolled type II diabetes mellitus patients. Behav Sci. 2017;7:62.

12. Pollock SE. Human responses to chronic illness: physiologic and psychosocial adaptation. Nurs Res. 1986;35:90-95.

13. American Diabetes Association (ADA). Standards of medical care in diabetes-2018. Diabetes Care. 2018;4:S56.
14. Polonsky WH, Fisher $\mathrm{L}$, Schikman $\mathrm{CH}$, et al. Structured self-monitoring of blood glucose significantly reduces $\mathrm{A} 1 \mathrm{C}$ levels in poorly controlled, noninsulin-treated type 2 diabetes: results from the Structured Testing Program study. Diabetes Care. 2011;34:262-267.

15. Miller KM, Beck RW, Bergenstal RM, et al. T1D exchange clinic network. Evidence of a strong association between the frequency of self-monitoring of blood glucose and hemoglobin A1c levels in T1D Exchange clinic registry participants. Diabetes Care. 2013;36:2009-2014.

16. Gellad WF, Zhao X, Thorpe CT, Mor MK, Good, CB, Fine MJ. Dual use of Department of Veterans Affairs and Medicare benefits and use of test strips in veterans with type 2 diabetes mellitus. JAMA Intern Med. 2015;175:26-34.

17. Grant RW, Huang ES, Wexler DJ, et al. Patients who self-monitor blood glucose and their unused testing results. Am J Manag Care. 2015;21:e119-e29.

18. American Association of Diabetes Educators (AADE). Learning how to inject insulin. https://www. diabeteseducator.org/docs/default-source/legacydocs/_resources/pdf/general/Insulin_Injection_ How_To_AADE.pdf. Accessed October 23, 2019.

19. Ong WM, Chua SS, Ng CJ. Barriers and facilitators to self-monitoring of blood glucose in people with type 2 diabetes using insulin: a qualitative study. Patient Preference Adherence. 2014;8:237-246.

20. Gucciardi E, Fortugno M, Senchuk A, Beanlands H, McCay E, Peel EE. Self-monitoring of blood glucose in the Black Caribbean and South Asian Canadians with non-insulin treated Type 2 diabetes mellitus: a qualitative study of patients' perspectives. BMC Endocr Disord. 2013;13:1-10.

21. Snoek FJ, Malanda UL, Wit M de. Self-monitoring of blood glucose: psychological barriers and benefits. Eur Diabetes Nurs. 2008;5(Autumn):112-115.

22. Peel E, Douglas M, Lawton J. Self-monitoring of blood glucose in type 2 diabetes: a longitudinal qualitative study of patients' perspectives. BMJ. 2007;335:493.

23. Anderson BJ, Vangsness L, Connell A, Butler D, Goebel-Fabbri A, Laffel LM. Family conflict, adherence, and glycaemic control in youth with short duration Type 1 diabetes. Diabetic Med. 2002;19:635-642.

24. Yoshioka N. Psychological reluctance to insulin therapy: as an illness side of diabetes mellitus. Diabetol Int. 2018;9:82-83. 
25. Bai X, Liu Z, Li Z, Yan D. The association between insulin therapy and depression in patients with type 2 diabetes mellitus: a meta-analysis. BMJ Open. 2018;8:e020062.

26. Taylor S, Fatima Y, Solomon S. Factors affecting the self-monitoring of blood glucose levels in Aboriginal patients findings from a remote community. Australian Indigenous Health Bulletin. 2017;17: 1-7.

27. van Dooren FE, Denollet J, Verhey FR, et al. Psychological and personality factors in type 2 diabetes mellitus, presenting the rationale and exploratory results from The Maastricht Study, a population-based cohort study. BMC Psychiatry. 2016;16:17.

28. Mollema ED, Snoek FJ, Heine RJ, van der Ploeg HM. Phobia of self-injecting and self-testing in insulintreated diabetes patients: opportunities for screening Diabet Med. 2001;18:671-674.

29. World Health Organization (WHO). WHO Guidelines on Drawing Blood: Best Practice in Phlebotomy. Geneva, Switzerland: WHO Press; 2010.

30. Nazmi AS, Khan SA, Hadithi DA. Self-monitoring of blood glucose level among diabetic patients in Muscat, Oman: a pilot study. Saudi J Health Sci. 2013;2:54-57.

31. Peyrot M, Rubin RR, Lauritzen T, et al. Psychosocial problems and barriers to improved diabetes management: results of the cross-national Diabetes Attitudes, Wishes, and Needs (DAWN) study. Diabet Med. 2005;22:1379-1385.

32. Polonsky WH, Henry RR. Poor medication adherence in type 2 diabetes: recognizing the scope of the problem and its key contributors. Patient Preference Adherence. 2016;10:1299-1307.

33. Reynolds RM, Strachan M. Home blood glucose monitoring in type 2 diabetes: regular monitoring is necessary only in some situations. $\mathrm{Br}$ Med $\mathrm{J}$. 2004;329:754-745.

34. Welschen LM, van Oppen P, Bot SD, Kostense PJ, Dekker JM, Nijpels G. Effects of a cognitive behavioral treatment in patients with type 2 diabetes when added to managed care; a randomized controlled trial. J Behav Med. 2013;36:556-566.

35. Cox DJ, Gonder-Frederick L, Ritterband L, et al. Blood glucose awareness training: what is it, where is it, and where is it going? Diabetes Spectr. 2006;19:43-49.

36. Funnell MM, Kruger DF, Spencer M. Self-management support for insulin therapy in type 2 diabetes. Diabetes Educ. 2004;30:274-280.

37. Kerr D, Fayers K. Continuous real-time glucose monitoring systems: time for a closer look. Pract Diab Int. 2008;25:37-41.

38. McAndrew LM, Horowitz CR, Lancaster KJ, et al. Association between self-monitoring of blood glucose and diet among minority patients with diabetes. J Diabetes. 2011;3:147-152.

39. Szymborska-Kajanek A PA, Hese R, Strojek K. Self-monitoring of blood glucose in the treatment of type 2 diabetes. Diabetes Res Clin Pract. 2009;86 (Suppl 1):S49-S52.

40. Polonsky WH, Fisher L, Schikman $\mathrm{CH}$, et al. Structured self-monitoring of blood glucose significantly reduces $\mathrm{A} 1 \mathrm{C}$ levels in poorly controlled, noninsulin-treated type 2 diabetes: results from the Structured Testing Program study. Diabetes Care. 2011;34:262-267.

41. Das-Munshi J, Stewart R, Ismail K, Bebbington PE, Jenkins R, Prince MJ. Diabetes, common mental disorders, and disability: findings from the UK National Psychiatric Morbidity Survey. Psychosomatic Med. 2007;69:543-550.

42. Kawamura T, Shioiri T, Takahashi K, Ozdemir V, Someya T. Survival rate and causes of mortality in the elderly with depression: a 15-year prospective study of a Japanese community sample, the Matsunoyama-Niigata suicide prevention project. J Investig Med. 2007;55:106-114.

43. Nicolucci A, Kovacs Burns K, Holt RI, et al. Diabetes attitudes, wishes and needs second study (DAWN2): cross-national benchmarking of diabetes-related psychosocial outcomes for people with diabetes. Diabetic Med. 2013;30:767-777. 